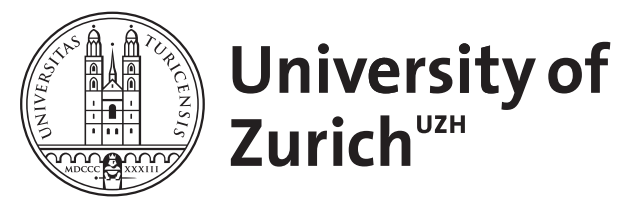

\title{
Male Genital Allometry in Scathophagidae (Diptera)
}

\author{
Hosken, D J ; Minder, A M ; Ward, P I
}

\begin{abstract}
Male genital structures are extremely divergent across species and sexual selection is largely responsible. Many sexually selected traits show positive allometry and have high phenotypic coefficients of variation $(\mathrm{CV})$. Sexually-selected genital traits that come into contact with females during copula may be an exception to this general pattern. We compared the within species size allometry of the genital claspers, mandibular palps, and testes in a comparative study across the Scathophagidae. We additionally compared the levels of phenotypic variation in these traits and in hind tibia length. Within species, claspers typically displayed negative allometry and had low CV, indicative of stabilizing selection. In contrast, testis size was more like sexually selected display traits, typically being positively allometric and having very large CV. Palps tended to be positively allometric or isometric, and intermediate in levels of phenotypic variation, much like leg length. In spite of intraspecific stabilizing selection on the genital claspers, there has been major divergence of these characters across species
\end{abstract}

DOI: https://doi.org/10.1007/s10682-005-1023-z

Posted at the Zurich Open Repository and Archive, University of Zurich

ZORA URL: https://doi.org/10.5167/uzh-155775

Journal Article

Published Version

Originally published at:

Hosken, D J; Minder, A M; Ward, P I (2005). Male Genital Allometry in Scathophagidae (Diptera).

Evolutionary Ecology, 19(5):501-515.

DOI: https://doi.org/10.1007/s10682-005-1023-z 
Research article

\title{
Male genital allometry in Scathophagidae (Diptera)
}

\author{
D.J. HOSKEN ${ }^{1,2, *}$, A.M. MINDER ${ }^{1}$ and P.I. WARD ${ }^{1}$ \\ ${ }^{1}$ Zoology Museum, The University of Zürich, Winterthurerstr. 190, 8057, Zürich, Switzerland; \\ ${ }^{2}$ Centre for Ecology and Conservation, University of Exeter in Cornwall, Tremough Campus, TR10 \\ 9EZ, Penryn, UK (*author for correspondence, e-mail: D.J.Hosken@exeter.ac.uk)
}

Received 22 December 2004; accepted 8 July 2005

Co-ordinating editor: V. Jormalainen

\begin{abstract}
Male genital structures are extremely divergent across species and sexual selection is largely responsible. Many sexually selected traits show positive allometry and have high phenotypic coefficients of variation (CV). Sexually-selected genital traits that come into contact with females during copula may be an exception to this general pattern. We compared the within species size allometry of the genital claspers, mandibular palps, and testes in a comparative study across the Scathophagidae. We additionally compared the levels of phenotypic variation in these traits and in hind tibia length. Within species, claspers typically displayed negative allometry and had low CV, indicative of stabilizing selection. In contrast, testis size was more like sexually selected display traits, typically being positively allometric and having very large CV. Palps tended to be positively allometric or isometric, and intermediate in levels of phenotypic variation, much like leg length. In spite of intraspecific stabilizing selection on the genital claspers, there has been major divergence of these characters across species.
\end{abstract}

Key words: allometry, genitalia, Scatophaga, sexual selection, testis size, variation

\section{Introduction}

Male genital morphology is extremely variable even when general morphology varies little. This is a conspicuous and comprehensive trend across animals (Eberhard, 1985). It is increasingly clear that sexual selection is the primary force driving genital divergence (e.g. Arnqvist, 1989, 1998; Dixson, 1998; Danielsson and Askenmo, 1999; Stockley, 2002; Fairbairn et al., 2003; House and Simmons, 2003), as Eberhard (1985, 1996, 1997, 1998) suggested it would be (reviewed in Hosken and Stockley, 2004). For example, a comparative study across insects, including flies, found that in polyandrous species, genitalia were about twice as divergent as in monandrous taxa (Arnqvist, 1998), and several recent studies document associations between male genital morphology and fertilization success (Arnqvist and Danielsson, 1999; Danielsson and Askenmo, 1999; House and Simmons, 2003; Rodríguez et al., 2003; reviewed in Hosken and Stockley, 2004). 
Many sexually selected traits show positive allometry relative to body size (Petrie, 1988, 1992; Green, 1992; Knell et al., 2004). For example, earwig forceps are positively allometric, and tend to show steeper allometric slopes in species where they are more exaggerated (Simmons and Tomkins, 1996). Similarly, eye-span in stalk-eyed flies is also positively allometric (Burkhardt et al., 1994). In contrast, sexually selected genitalia, including male structures that are brought into contact with females in precise ways during copulation (following Eberhard's (1985) definition of genitalia), may be under stabilizing selection and hence display low allometric values $(\beta<1.0)$ (Eberhard et al., 1998). The most comprehensive test of this idea in 20 species of insects and spiders found that in most species male genital characters were indeed negatively allometric, leading to the suggestion that selection favoured one size to fit all females (Eberhard et al., 1998). This study was subsequently criticised primarily on methodological grounds because the authors used least-squares linear regression to obtain their allometric slopes, which may be inappropriate when there is measurement error in both the $x$ - and $y$-variables (Green, 1999; also see Eberhard et al., 1999). Nevertheless, negative genital allometry has been reported for several other invertebrate taxa (e.g. Schmitz et al., 2000; Uhl and Vollrath, 2000; Tatsuta et al., 2001; Bernstein and Bernstein, 2002; Eberhard, 2002), although again, studies often used Type I regression. More recently, positive allometry has also been reported in several groups (Kelly et al., 2000; Lüpold et al., 2004), and additional work is needed to evaluate the generality of Eberhard et al.'s (1998) claim that negative genital allometry is the norm (one size fits all).

In addition to allometric considerations, it has also been suggested that sexually selected traits could display different levels of phenotypic variation compared to non-sexually selected traits. For example, if sexual selection on male traits tends to deplete their genetic variation (Kirkpatrick and Ryan, 1991), these traits may have lower coefficients of variation (CV) than nonsexual traits (Eberhard et al., 1998). Alternatively, sexual selection may favour modifier alleles that increase the $\mathrm{CV}$ of sexually selected traits (Pomiankowski and Møller, 1995; Rowe and Houle, 1996), and there is some evidence that the $\mathrm{CV}$ of these characters tends to be greater (e.g. Alatalo et al., 1988; Pomiankowski and Møller, 1995). CV differences may arise for two reasons, differences in dispersion or allometry (see Fig. 1 in Eberhard et al., 1998), and most studies typically only examine one or the other distribution feature. As a result of this, and generally to evaluate the form of selection on genitalia, studies quantifying intra-specific variation in genital structures are required (Arnqvist, 1998; Gwynne, 1998).

Here we report on an investigation of genital allometry across the Scathophagidae. These flies are found world-wide, with around 250 species described. In Switzerland about 45 species occur (Merz et al., 1998), including the 
well studied yellow dung fly (Scathophaga stercoraria (L.)). Previous studies of copula in this species indicate male genital claspers (anterior surstylus: Zaka-ur-Rab, 1979) are used to hold onto the tip of the female abdomen during copula, squeezing them at about the point where the spermathecal ducts enter the copulatory bursa (Hosken et al., 1999), and Eberhard's (1985) definition of genitalia includes these structures (also see Arnqvist, 1989). Darwin (1874) also suggested that structures such as these that hold females during copula would be sexually selected, perhaps preventing rival males from takingover the female during copula (e.g. Parker, 1970). Clasper use in male-male competition in this instance may also imply stabilising selection (if they are too small or too large they cannot hold average sized females). Additionally, the movement of the claspers that occurs during copulation in at least some of our study species is consistent with copulatory courtship (Eberhard, 1994, 2001), and in another fly, movement of the male claspers during copula influences male fertilization success (Otronen, 1998). In this study we investigated the within species allometry (relative to body size) and variation in the size of claspers, mandibular palps, and testes in 13 species (from 4 genera) where we had large enough samples to obtain reasonable allometry estimates. We also compared variation in leg size with these other characters. Specifically we asked, how do the claspers and other characters scale with body size, and how variable are these traits?

\section{Materials and methods}

Flies were collected with a net at several sites in Switzerland, predominantly in Kantons Zürich and Schwyz, brought to the laboratory alive and then frozen at $-20{ }^{\circ} \mathrm{C}$. Full collection details are given in Minder (2002), but we note here that with the exception of Scathophaga cineraria, all species used in this study were either collected at multiple sites or times from late April until late July 2001. The collection from multiple sites and time should not represent a problem in terms of our allometry estimation since the available evidence from flies of this family, and other smaller dung flies, suggests that there is no population structure across Switzerland (Kraushaar et al., 2002). It seems unlikely to us that selection for radically different allometry could occur between spring and summer in what appear to be single panmictic populations, and although there do appear to be size differences between some sites of one family member, evidence for allometric associations that have been investigated, suggest they do not vary across collection site in this species (Kraushaar and Blanckenhorn, 2002). Species were identified using published keys (Sack, 1937; Hackman, 1956), and by comparison with identified dried specimens in the collections at the Zoology Museum in Zürich, which is where the specimens 
we collected are now held. For all flies the length of one hind tibia (HTL) was measured under a binocular microscope before dissection (see below) and used as an indicator of body size, which is standard in these species (e.g. Sigurjonsdottir and Parker, 1980; Ward and Simmons, 1991; Hosken and Ward, 2001).

Testes were dissected from individual males of each species and immediately transferred to a droplet of Ringer's solution $(\mathrm{pH}=7)$ on a glass slide. The area of each testis was measured. Testis area measured in this way has been shown to accurately represent the 3-dimensional size of the testes (Minder et al., 2005), and the general shape of the testes was the same for each species. The rear portion of the abdomen was then cut free and after removing most of the abdomen from the clasper, it was transferred to a drop of Ringer's solution on a glass slide and then covered with a coverslip under light pressure to flatten the structure for accurate measurement. Then the perimeter (hereafter, size) of the clasper was measured. While this measure obviously does not capture the full complexity of clasper morphology, previous work indicates that such simple linear measures frequently provide as much information as more complex procedures that capture more shape information (e.g. Arnqvist and Thornhill, 1998; House and Simmons, 2003). Therefore, while we have greatly simplified clasper structure by using size (perimeter), this measure still retains useful information, especially since we are primarily interested in allometry here. This is analogous to work on beetles where simple size measures of genital structures explained more than $50 \%$ of the variation in male fertilization success (House and Simmons, 2003). Similarly, the mandibular palps (a mouth appendage conceptually similar to the clasper) were removed from each male, and the perimeter was also measured (hereafter size) using the same methods. Testis, clasper, and palp measurements were carried out with digitized video images captured with an image analysis system (KS 3003.0 (Zeiss)). Seven to twenty three males per species were dissected and measured for allometric associations (number of species $=13$; mean number of males/species $=$ ca. 17). Sample sizes vary somewhat because of dissection difficulties. Additionally, several individuals per species were measured twice (blind) to test the accuracy of measurements. Regression (ordinary least squares (OLSR)) of measurement 1 on measurement 2 indicated all these measures were highly repeatable (e.g. Clasper: $r^{2}=0.99 ; \beta=1.002 ; F_{1,34}=49632 ; p<0.0001$; and also see Minder et al., 2005 for additional verification of our measurement accuracy). We note here that although traits were not remounted between measurement sessions (for some traits, e.g. testis, this was impossible), we were only interested in trait size (not subtle differences like fluctuating asymmetry) and all traits were treated the same way (flattened on a slide and measured), therefore any difference in allometry are extremely unlikely to be due to systematic biases in mounting and measurement. 
As outlined above, male characters under sexual selection are generally thought to show allometric slope values $>1.0$ when scaled against body size. In contrast, male structures (e.g. genitalia) that are brought into contact with females in precise ways during copulation may display low allometric values $(\beta<1.0)$ (Eberhard et al., 1998). We therefore performed regression of clasper, palp and testis size on HTL within the different species. We used major axis (model II) regression (MA) (with the appropriate SE in both $\mathrm{x}$ and $\mathrm{y}$ directions) (using a spreadsheet provided by Wolf Blanckenhorn), in addition to OLSR (which reflects error only in y), because both axis are equally subject to measurement error (Sokal and Rohlf, 1981; and see Green, 1999). The significance of the allometry (differences from 0 ) was assessed using t-tests of the OLSR results (following Tatsuta et al., 2001). This is conservative as the errors in the OLSR are larger than in the MA. We also used $t$-test to test if slopes differed from 1 . We also calculated the CV (standard deviation divided by the mean) of the claspers, palps, testes and HTL to see if the variation in these structures differed. Prior to analyses, area data (testis) were square-root transformed so that we were comparing linear measures with linear measures (e.g. Minder et al., 2005), and all data were natural log transformed: after transformation all were normally distributed (Kolmogorov-Smirnov test of normality with Lillifors correction; all variables $p>0.59$ ).

\section{Results}

Testis allometry was typically statistically significant (10 of 13 species), but in only one instance was the OLSR slope greater than 1 (Table 1). However, Student's $t$-tests of the significant slopes indicated that in all species the OLSR slopes were not significantly different from 1 (all $|t|<1.67$; all $p>0.1$ ). Major axis slopes were typically greater than 1 (11 of 13 species), and in some instances were greater than 2 (Table 1). Student's $t$-tests of the MA slopes indicated that for 9 of 13 species the slopes were greater than 1 (C. albipes, $N$. nervosa, $S$. cineraria and $S$. suilla slopes not significantly greater than 1 , $|t|<1.94 ; p>0.05$. All other species $|t|>2.14 ; p<0.05$ ). A one-sample $t$-test of MA slopes across species indicated that the mean slope was significantly greater than 1 (mean $\pm \mathrm{SE}$ MA slope $=1.76 \pm 0.24 ; t=3.19 ; p=0.008$ ), but not significantly different from $2(t=-0.98 ; p=0.34)$. Although testis size (e.g. Hosken and Ward, 2001) and allometry clearly evolve rapidly (Table 1) and hence probably do not need phylogenetic control (Losos, 1999 and see e.g. Eberhard et al., 1998), if we nonetheless used Felsenstein's (1985) method to calculate independent contrasts in testis allometry based on Bernasconi et al.'s (2000) phylogeny, testis allometry controlling for phylogeny was still significantly greater than 1 (mean \pm SE MA slope using independent 
Table 1. The ordinary least squares regression (and associated statistics) and MA slope (bold) and CV (\%, italics) results for each species' testis size allometry (relative to body size (HTL))

\begin{tabular}{|c|c|c|c|c|c|}
\hline Species $(\mathrm{N})$ & Slope $( \pm$ SE $)$ & & $r$ & $t$ & $p$ \\
\hline \multirow[t]{2}{*}{ Cordilura albipes (9) } & $0.984( \pm 0.31)$ & & 0.74 & 3.13 & $<0.001$ \\
\hline & $1.05( \pm 0.14)$ & $20 \%$ & & & \\
\hline \multirow[t]{2}{*}{ C. ciliata $(20)$} & $0.207( \pm 0.35)$ & & 0.14 & 0.59 & 0.56 \\
\hline & $3.44( \pm 0.19)$ & $13 \%$ & & & \\
\hline \multirow[t]{2}{*}{ C. pubera $(20)$} & $0.42( \pm 0.28)$ & & 0.33 & 1.49 & 0.15 \\
\hline & $1.98( \pm 0.19)$ & $9 \%$ & & & \\
\hline \multirow[t]{2}{*}{ Norellia alpestris (7) } & $1.28( \pm 0.40)$ & & 0.82 & 3.22 & 0.023 \\
\hline & $1.84( \pm 0.18)$ & $20 \%$ & & & \\
\hline \multirow[t]{2}{*}{ N. nervosa (9) } & $0.90( \pm 0.11)$ & & 0.95 & 8.00 & $<0.001$ \\
\hline & $0.94( \pm 0.08)$ & $34 \%$ & & & \\
\hline \multirow[t]{2}{*}{ N. spinimana $(20)$} & $0.78( \pm 0.32)$ & & 0.50 & 2.45 & 0.024 \\
\hline & $2.36( \pm 0.15)$ & $31 \%$ & & & \\
\hline \multirow[t]{2}{*}{ N. striolata $(20)$} & $0.81( \pm 0.22)$ & & 0.65 & 3.65 & 0.002 \\
\hline & $1.42( \pm 0.14)$ & $82 \%$ & & & \\
\hline \multirow[t]{2}{*}{ Phrosia albilabris (20) } & $0.74( \pm 0.21)$ & & 0.63 & 3.48 & 0.003 \\
\hline & $1.30( \pm 0.14)$ & $14 \%$ & & & \\
\hline \multirow[t]{2}{*}{ Scathophaga cineraria (18) } & $0.58( \pm 0.25)$ & & 0.51 & 2.35 & 0.032 \\
\hline & $1.33( \pm 0.17)$ & $27 \%$ & & & \\
\hline \multirow[t]{2}{*}{ S. furcata (19) } & $0.60( \pm 0.25)$ & & 0.51 & 2.44 & 0.026 \\
\hline & $1.39( \pm 0.18)$ & $65 \%$ & & & \\
\hline \multirow[t]{2}{*}{ S. stercoraria (23) } & $0.31( \pm 0.32)$ & & 0.21 & 0.98 & 0.34 \\
\hline & $3.53( \pm 0.17)$ & $60 \%$ & & & \\
\hline \multirow[t]{2}{*}{ S. suilla (19) } & $0.75( \pm 0.15)$ & & 0.77 & 5.067 & $<0.001$ \\
\hline & $0.98( \pm 0.11)$ & $22 \%$ & & & \\
\hline \multirow[t]{2}{*}{ S. taeniopa (20) } & $0.67( \pm 0.23)$ & & 0.56 & 2.87 & 0.010 \\
\hline & $1.38( \pm 0.15)$ & $69 \%$ & & & \\
\hline
\end{tabular}

contrasts $=1.71 \pm 0.49 ;$ one-sample $t$-test, $t=5.34 ; p=0.0005 ; \mathrm{df}=9$ ) (note that $N$. alpestris and $N$. nervosa are not included in the phylogeny and hence are excluded from contrast calculations). Based on all the above, it appears that overall testis allometry is positive.

In contrast, OLSR indicated that in all species regression slopes for the male claspers against body size were less than 1 (Table 2). In 5 species the slopes were significant and negatively allometric $(t<-3.92 ; p<0.01)$, while for 7 species, associations were flat and slopes were not statistically greater than 0 (Table 2). The exception to this pattern was $C$. albipes (slope $>$ zero (Table 2) but not different from $1 ; t=-0.85 ; p>0.20)$. The MA results were broadly similar. Only one of 13 species (C. ciliata) had an allometric slope greater than 1 (Table $2 ; t=4.40 ; p<0.001$ ). Ten other species had a MA slope less than 1 $(t<-3.0 ; p<0.01)$, and two species the slope was not significantly different from 1 (C. albipes, $t=-0.83 ; p>0.2$. C. pubera, $t=-2.0 ; p>0.2$ ). A onesample $t$-test of MA slopes across species indicated that the mean slope was significantly less than 1 (mean \pm SE MA slope $=0.48 \pm 0.14 ; t=-3.66$; $p=0.003$ ), so overall, claspers were negatively allometric. As above, size and 
Table 2. The ordinary least squares regression results for each species (and associated statistics) of clasper size allometry (relative to body size (HTL)), plus MA slopes (bold) and CV of claspers (\% bold italics) and HTL ( $\%$ italics). Note that all of the OLSR slopes that were greater than 0 , were significantly less than 1 , except for $C$. albipes (see text)

\begin{tabular}{|c|c|c|c|c|c|c|}
\hline Species $(\mathrm{N})$ & Slope $( \pm \mathrm{SE})$ & & $r$ & & $t$ & $p$ \\
\hline \multirow{2}{*}{ Cordilura albipes (9) } & $0.93( \pm 0.082)$ & & 0.97 & & 11.34 & $<0.001$ \\
\hline & $0.95( \pm 0.06)$ & $14.1 \%$ & & $14.3 \%$ & & \\
\hline \multirow[t]{2}{*}{ C. ciliata (19) } & $0.31( \pm 0.27)$ & & 0.26 & & 1.12 & 0.28 \\
\hline & $1.88( \pm 0.20)$ & $4.4 \%$ & & $4.0 \%$ & & \\
\hline \multirow[t]{2}{*}{ C. pubera (20) } & $0.10( \pm 0.22)$ & & 0.11 & & -0.45 & 0.66 \\
\hline & $0.57( \pm \mathbf{0 . 2 2})$ & $3.7 \%$ & & $3.9 \%$ & & \\
\hline \multirow[t]{2}{*}{ Norellia alpestris (7) } & $0.44( \pm 0.10)$ & & 0.88 & & 4.31 & 0.008 \\
\hline & $0.41( \pm 0.13)$ & $3.5 \%$ & & $6.9 \%$ & & \\
\hline \multirow[t]{2}{*}{ N. nervosa (9) } & $0.49( \pm 0.13)$ & & 0.81 & & 3.85 & 0.005 \\
\hline & $0.51( \pm 0.14)$ & $5.6 \%$ & & $8.9 \%$ & & \\
\hline \multirow[t]{2}{*}{ N. spinimana $(20)$} & $0.11( \pm 0.14)$ & & 0.18 & & 0.79 & 0.44 \\
\hline & $0.17( \pm \mathbf{0 . 1 8})$ & $3.8 \%$ & & $6.0 \%$ & & \\
\hline \multirow[t]{2}{*}{ N. striolata $(20)$} & $0.11( \pm 0.12)$ & & 0.21 & & 0.92 & 0.37 \\
\hline & $0.14( \pm 0.16)$ & $2.9 \%$ & & $5.2 \%$ & & \\
\hline \multirow[t]{2}{*}{ Phrosia albilabris (20) } & $-0.001( \pm 0.14)$ & & $<0.01$ & & -0.01 & 0.99 \\
\hline & $-0.002( \pm 0.18)$ & $4.3 \%$ & & $7.0 \%$ & & \\
\hline \multirow[t]{2}{*}{ Scathophaga cineraria (17) } & $-0.13( \pm 0.20)$ & & 0.24 & & -0.67 & 0.52 \\
\hline & $-0.19( \pm 0.18)$ & $4.7 \%$ & & $8.6 \%$ & & \\
\hline \multirow[t]{2}{*}{ S. furcata (20) } & $0.38( \pm 0.12)$ & & 0.58 & & 2.99 & 0.008 \\
\hline & $0.49( \pm 0.14)$ & $6.8 \%$ & & $10.2 \%$ & & \\
\hline \multirow[t]{2}{*}{ S. stercoraria (19) } & $0.48( \pm 0.13)$ & & 0.66 & & 0.37 & 0.002 \\
\hline & $0.61( \pm 0.13)$ & $9.6 \%$ & & $12.9 \%$ & & \\
\hline \multirow[t]{2}{*}{ S. suilla (19) } & $0.29( \pm 0.14)$ & & 0.43 & & 1.98 & 0.064 \\
\hline & $0.43( \pm 0.17)$ & $6.0 \%$ & & $9.0 \%$ & & \\
\hline \multirow[t]{2}{*}{ S. taeniopa (19) } & $0.22( \pm 0.12)$ & & 0.41 & & 1.80 & 0.091 \\
\hline & $0.31( \pm 0.14)$ & $5.9 \%$ & & $11.2 \%$ & & \\
\hline
\end{tabular}

allometry of the claspers have clearly evolve rapidly (this is true of genitalia generally which is why they are used in species identification, e.g. Sack (1937) and hence probably do not need phylogenetic control (Losos, 1999), if we nonetheless used Felsenstein's (1985) method to calculate independent contrasts in clasper allometry based on Bernasconi et al.'s (2000) phylogeny, clasper allometry controlling for phylogeny was still significantly less than 1 (mean \pm SE MA slope using independent contrasts $=0.25 \pm 0.14$; one-sample $t$-test, $t=-17.24 ; p<0.0001$; df $=9$ ) (note that $N$. alpestris and $N$. nervosa are not included in the phylogeny and hence are excluded from contrast calculations). Overall our data indicate clasper allometry tends to be negative.

We also looked at the allometry of the mandibular palps (Table 3). OLSR indicated there was significant allometry in all species (Table 3) except $C$. cilliata and $C$. pubera (Table 3 ), but allometry was not significantly greater than 1 in any species (all $|t|<1.8$; all $p>0.05$ ). MA slopes were greater than 1 in all 
Table 3. The ordinary least squares regression (and associated statistics) and MA slope (bold) and CV (\%, italics) results for each species' mandible palp size allometry (relative to body size (HTL))

\begin{tabular}{|c|c|c|c|c|c|}
\hline Species $(\mathrm{N})$ & Slope $( \pm$ SE $)$ & & $r$ & $t$ & $p$ \\
\hline \multirow[t]{2}{*}{ Cordilura albipes (10) } & $1.03( \pm 0.11)$ & & 0.98 & 9.34 & $<0.001$ \\
\hline & $1.07( \pm \mathbf{0 . 0 6})$ & $16 \%$ & & & \\
\hline \multirow[t]{2}{*}{ C. ciliata $(20)$} & $0.48( \pm 0.29)$ & & 0.36 & 1.63 & 0.12 \\
\hline & $1.34( \pm 0.16)$ & $5.2 \%$ & & & \\
\hline \multirow[t]{2}{*}{ C. pubera (20) } & $1.13( \pm 0.78)$ & & 0.34 & 1.55 & 0.14 \\
\hline & $3.29( \pm 0.42)$ & $12 \%$ & & & \\
\hline \multirow[t]{2}{*}{ Norellia alpestris (7) } & $0.96( \pm 0.29)$ & & 0.83 & 3.35 & 0.02 \\
\hline & $1.16( \pm 0.16)$ & $8 \%$ & & & \\
\hline \multirow[t]{2}{*}{ N. nervosa (10) } & $1.04( \pm 0.12)$ & & 0.95 & 8.60 & $<0.001$ \\
\hline & $1.09( \pm 0.15)$ & $10 \%$ & & & \\
\hline \multirow[t]{2}{*}{ N. spinimana $(20)$} & $1.38( \pm 0.28)$ & & 0.76 & 4.94 & $<0.001$ \\
\hline & $1.82( \pm 0.12)$ & $11 \%$ & & & \\
\hline \multirow[t]{2}{*}{ N. striolata (20) } & $0.76( \pm 0.20)$ & & 0.67 & 3.86 & 0.001 \\
\hline & $1.13( \pm 0.18)$ & $6 \%$ & & & \\
\hline \multirow[t]{2}{*}{ Phrosia albilabris (20) } & $0.83( \pm 0.18)$ & & 0.73 & 4.59 & $<0.001$ \\
\hline & $1.13( \pm 0.14)$ & $8 \%$ & & & \\
\hline \multirow[t]{2}{*}{ Scathophaga cineraria (18) } & $1.13( \pm 0.2)$ & & 0.80 & 5.43 & $<0.001$ \\
\hline & $1.41( \pm 0.29)$ & $11 \%$ & & & \\
\hline \multirow[t]{2}{*}{ S. furcata (20) } & $1.22( \pm 0.15)$ & & 0.88 & 8.08 & $<0.001$ \\
\hline & $1.38( \pm 0.18)$ & $14 \%$ & & & \\
\hline \multirow[t]{2}{*}{ S. stercoraria (24) } & $1.12( \pm 0.08)$ & & 0.94 & 13.58 & $<0.001$ \\
\hline & $1.18( \pm 0.05)$ & $15 \%$ & & & \\
\hline \multirow[t]{2}{*}{ S. suilla (19) } & $0.88( \pm 0.14)$ & & 0.83 & 6.30 & $<0.001$ \\
\hline & $1.06( \pm 0.08)$ & $9 \%$ & & & \\
\hline \multirow[t]{2}{*}{ S. taeniopa (18) } & $1.06( \pm 0.06)$ & & 0.98 & 18.7 & $<0.001$ \\
\hline & $1.09( \pm 0.05)$ & $12 \%$ & & & \\
\hline
\end{tabular}

species, but were only significantly so for 5 species (C. ciliata, C. pubera, $N$. spinimana, $S$. furcata and $S$. stercoraria). $|t|>2.11 ; p<0.05$. All other species $|t|<1.8 ; p>0.05$ ). Of the 5 species with a MA slope statistically greater than 1 , all were less than 2 except for $C$. pubera. Nevertheless, one-sample $t$-tests indicated that MA slopes were significantly greater than 1 across species (mean $\pm \mathrm{SE}$ MA slope $=1.39 \pm 0.60 ; t=2.36 ; p=0.036$ ), but overall slopes were less than $2(t=-3.58 ; p=0.004)$ (Table 3$)$. If we used Felsenstein's (1985) method to calculate independent contrasts in palp allometry based on Bernasconi et al.'s (2000) phylogeny, palp allometry controlling for phylogeny was also significantly greater than 1 (mean \pm SE MA slope using independent contrasts $=1.46 \pm 0.35$; one-sample $t$-test, $t=-4.16 ; p=0.002$; $\mathrm{df}$ $=9$ ) (note that $N$. alpestris and $N$. nervosa are not included in the phylogeny and hence are excluded from contrast calculations). Overall our data indicate palp allometry tends to be slightly positive.

Because we had a range of sample sizes across the species $(n=$ between 7 and 23) which could potentially influence the accuracy of our MA slope estimates, we also looked to see if either the MA slopes or the SE of the slopes 
were associated with sample size, but there were no statistically significant associations $(F<2.5 ; p>0.14)$, except for the error of the clasper estimates which were positively associated with sample size $\left(\beta=0.005 ; F_{1,11}=7.8\right.$; $\left.p=0.02 ; r^{2}=0.41\right)$. However, this association was driven by the very small error for $C$. albipes, which was greater than 2 SD's from the mean, and if this species was removed became non-significant $(p=0.12)$.

Repeated measures GLM indicated that MA slopes and CV varied across traits types $\left(F_{2,36}=17.53 ; p=0.0001\right)$. We then used paired t-tests to do focused post-hoc comparisons. Comparison of the MA allometric slopes of claspers and testes within species indicated testis slopes were significantly greater than claspers (mean MA slope: testis $=1.76$, clasper $=0.48 ; \mathrm{df}=12$; paired- $t=6.23 ; p<0.0001)$. We additionally looked to see if MA slopes for clasper allometry were associated with testis size but there was no significant correlation between the two (OLSR slope $=-0.563 ; r=0.26 ; F_{1,11}=0.81$; $p=0.388$ ), indicating that steeper slopes were not found in species with greater sexual selection: testis size is a strong correlate of post-copulatory sexual selection (see discussion). Claspers also had significantly shallower slopes than palps (mean MA slope: claspers $=0.48$, palps $=1.40$; $\mathrm{df}=12$; paired- $t=-4.191 ; p=0.0013)$. Finally, comparing testis and palp slopes indicated no significant differences between the two (mean MA slope: palps $=1.40$, testis $=1.76$; $\mathrm{df}=12$; paired- $t=1.40 ; p=0.19$ ). Our interpretation of all these paired comparisons remains unchanged after correction for multiple testing.

The $\mathrm{CV}$ of the various traits varied markedly (mean $\% \pm$ SE: testis $=35.8 \pm$ 6.8 ; claspers $=5.8 \pm 0.85$; palps $=10.6 \pm 0.92$; and $\mathrm{HTL}=8.3 \pm 0.9)$. The mean CV of testes (range ca. 8-81\%) was significantly greater than either clasper, palp or HTL (paired $t$-tests: $t>3.7 ; p<0.003$ ), and in the range of CV reported for some sexually selected (but non-genital) traits (ca. 22\%, Pomiankowski and Møller, 1995) (one-sample $t$-test; $t=2.04 ; p=0.064$ ). However, the testis CV is clearly greater than values reported by Eberhard et al. (1998) (ca. 6-7\%). There were no associations between the $\mathrm{CV}$ of clasper or palp size and testis size (with or without including body size) (OLSR $t<-1.76 ; p>0.10$ ). Comparing the CV of palps and claspers indicated that claspers were less variable than palps (paired $t$-test: $t=-7.68 ; p<0.0001)$, but there was a significant positive association between variability in the two appendages (Fisher's $Z$-test: $Z=3.123$; $p=0.0018)$. For most species the CV of HTL was also greater than that of the clasper (Table 2), and a paired $t$-test indicated that overall the difference was statistically significant (df $=12 ; t=5.6 ; p=0.0001$ ). However, neither HTL or clasper $\mathrm{CV}$ differed significantly from values reported for other genital or nongenital traits in insects and spiders (Eberhard et al., 1998: genital CV $=6.5 \%$, one-sample $t$-test $|t|<2.02 ; p>0.067$; non-genital CV $=6.9 \%$, one-sample $t$-test $|t|<1.60 ; p>0.14$ ), but the $\mathrm{CV}$ of mandibular palps and testes differed from 
510

both $(t>3.90 ; p<0.0018)$. Palps and testes were also more variable than leg length (paired $t$-test: $|t|>3.64 ; p=0.003$ ). The differences in CV for testis and claspers or palps appears to be primarily due to the slope differences as paired $t$-tests of a measure of dispersion in the data sets (the $r^{2}$ values from the OLSR of testis, palp and clasper size on HTL) found no significant differences $(t<1.025$, $p>0.33$ ). Again, our interpretation of these $\mathrm{CV}$ comparisons remains unchanged after correction for multiple testing.

\section{Discussion}

There is a general consensus that male genitalia are subject to sexual selection (reviewed in Eberhard, 1985; Hosken and Stockley, 2004). In spite of this, and in contrast to many sexually selected traits, male genitalia appear to show negative allometry in most invertebrates studied (e.g. Eberhard et al., 1998; Tatsuta et al., 2001; Bernstein and Bernstein, 2002). Consistent with this general genital pattern, and regardless of the analysis performed (OLSR or MA), the intraspecific allometric slopes of clasper size found here were usually less than 1. The most obvious and extreme exception to this pattern was the MA slope calculated for Cordilura ciliata where the slope was positively allometric.

Overall, our findings provide support for the idea that "one size fits all" (Eberhard et al., 1998), since in most instances (7 of 13 species) the OLSR allometric slopes did not significantly differ from zero, and for 5 the slope was less than 1, MA slopes tended to be less than 1 (10 of 13 species), and over all species (using independent contrast or species values), the mean MA slope was less than one. Eberhard et al. (1998) list potential reasons why this may be, including the idea that males are likely to be selected to fit the average sized female when there is no size-assortative mating (which seems to be the case in at least some of the flies we studied). This assumes that the female structures interacting with male genitalia either have a unimodal distribution or are also negatively allometric, for which there is some evidence (e.g. Eberhard et al., 1998; Gage, 1998). While our results support the one-size-fits-all hypothesis, it also serves to further highlight what appears to be fundamental differences in genital allometry between vertebrates (positive allometry, e.g. Lupold et al., 2004) and invertebrates (negative allometry, e.g. this study), but exactly why there is this discrepancy is unclear.

Our interpretation of why claspers show negative allometry assumes that genital claspers are subject to post-copulatory sexual selection. While this is the general pattern (reviewed in Hosken and Stockley, 2004), work on one of our study species (S. stercoraria) found paired and unpaired males in the field did not differ in clasper length (Blanckenhorn et al., 2003). However, that study 
only considers one component of sexual selection. Post-copulatory sexual selection is the most likely influence of genital form (e.g. Eberhard, 1994, 2001), and this remains to be investigated (also see Grafen, 1987). Additionally, while we acknowledge that across-species patterns provide little information on within-species selection, comparative data nonetheless indicates that claspers are subject to sexual selection across species (Minder, 2002).

In any case, the negative allometry for claspers indicates they are probably subject to stabilizing selection. In accordance with this, the CV for clasper size was smaller than those of leg length, palp and testis size. Similar patterns of variation in genitalia have been reported in other insects (e.g. Arnqvist and Thornhill, 1998; House and Simmons, 2003). It is also possible that there is little genetic variation for clasper size or that the genes controlling clasper size are linked to other genes themselves under stabilizing selection (Tatsuta et al., 2001). If this were the case however, it would only explain the low CV for claspers but not the low allometric slopes (Tatsuta et al., 2001). Furthermore, the claspers are extremely divergent (hence their use in species keys: e.g. Hackman, 1956), indicating considerable evolutionary potential (e.g. Eberhard, 1985), and thus low allometric values and low phenotypic CV need not be incompatible with rapid evolutionary divergence (cf. Eberhard et al., 1998). Moreover, as we show here, allometric values can vary considerably in closely related species.

Unlike claspers, testis size shows phenotypic patterns similar to many other sexually selected traits, and there is clear evidence that testes are subject to post-copulatory sexual selection generally (e.g. Harcourt et al., 1981; Hosken, 1997, 1998; Stockley et al., 1997; reviewed in Parker et al., 1997; Gage and Freckleton, 2003) and in insects, including flies (e.g. Gage, 1994; Hosken and Ward, 2001; Pitnick et al., 2001). Testes are also frequently positively allometric (e.g. Gage et al., 1995; Pitnick, 1996; Tomkins and Simmons, 2002), and have high $\mathrm{CV}$. What is surprising is that $S$. stercoraria is one of the species to show no significant testis allometry using OLSR. Previous studies have found positive allometry in this fly, albeit in laboratory raised individuals (e.g. Hellriegel and Blanckenhorn, 2002). This difference between studies highlights the problem of using testis size from field captured animals to estimate testis allometry: if males have copulated recently, frequently or have not yet achieved full sexual maturity, testis size measures will be somewhat more variable (see e.g. Ward and Simmons, 1991). This caveat must be kept in mind when interpreting our testis (allometry and CV) results, but importantly for our overall conclusions, positive allometry for testis size has frequently been reported in other taxa (e.g. Tomkins and Simmons, 2002).

In contrast to claspers, mandibular palps tended to be slightly positively allometric or isometric. We have no current reason to believe that the palps are sexually selected, and they do not contact females during copula in at least 
some species we study. If, as it currently appears, palps are not sexually selected, this finding highlights the point that positive allometry need not always be indicative of sexual selection. Our reason for including the palps here was merely to contrast another small appendage with the clasper, and as we show the allometry of these two structures greatly differ. What we now need to do is look to see if there is any evidence of sexual selection on palps within species.

Our finding that the $\mathrm{CV}$ for clasper size is lower than the CV for two general morphological traits (HTL and palps) is in partial agreement with previous results. Eberhard et al. (1998) reported CV of about $6.5 \%$ in genital characters (we found $5.8 \pm 0.8 \%$ ), but they found no significant difference between nongenital and genital CV, unlike here. Similarly, House and Simmons (2003) found genital traits were about as variable as general morphology. Our finding for claspers, but not testis, also differs markedly from findings for some other sexually selected characters (e.g. CV of about $22.3 \%$ in Pomiankowski and Møller, 1995), although the CV of hind tibia length (about $8.3 \pm 0.9 \%$ of trait size) is not significantly different from values for general morphological traits reported previously (e.g. Pomiankowski and Møller, 1995; Eberhard et al., 1998; House and Simmons, 2003). Palps were more variable though. It should also be noted that $\mathrm{CV}$ of the genital claspers were not associated with testis size, which indicates that variation in clasper size did not covary with sexual selection intensity. As correctly pointed out by Eberhard et al. (1998), differences in trait $\mathrm{CV}$ may be due to either slope or dispersion disparity. From our data, $r^{2}$ s were about the same for regression of the various traits on body size, but slopes clearly differed.

In conclusion, as appears to be the case with many genital characters, the allometry of clasper size was typically negative, and the CV was small, both of which indicates stabilizing selection on clasper size within scathophagids. Interestingly, what appears to be stabilizing selection on genital structures within these species has not stopped rapid divergence of these characters across taxa.

\section{Acknowledgements}

We thank Joe Tomkins, Rhonda Snook, Gabriele Uhl, Wolf Blanckenhorn, Mhairi McFarlane and especially Bill Eberhard for comments on previous versions which greatly improved the manuscript and for general discussion of matters genitalic. We also thank Wolf for kindly providing the spreadsheet used to calculate the MA slopes, and Veijo Jormalainen and two referees whose comments and care not only greatly improved the manuscript, but also helped us avoid some analytical errors. This work was supported by the SNF. 


\section{References}

Alatalo, R., Hoglund, J. and Lundberg, A. (1998) Patterns of variation in tail ornament size in birds. Biological Journal of the Linnean Society 34, 363-374.

Arnqvist, G. (1998) Comparative evidence for the evolution of genitalia by sexual selection. Nature 393, 784-786

Arnqvist, G. (1989) Sexual selection in a water strider: the function, mechanism of selection and heritability of a male grasping apparatus. Oikos 56, 344-350.

Arnqvist, G. and Danielsson, I. (1999) Copulatory behaviour, genital morphology, and male fertilization success in water striders. Evolution 53, 147-156.

Arnqvist, G. and Thornhill, R. (1998) Evolution of animal genitalia: patterns of phenotypic and genotypic variation and condition dependence of genital and non-genital morphology in water striders (Heteroptera: Gerridae: Insecta). Genet. Res. 71, 193-212.

Bernasconi, M., Pawlowski, J., Valsangiacomo, C., Piffaretti, J.-C. and Ward, P.I. (2000) Phylogeny of the Scathophagidae (Diptera, Calyptratae) based on mitochondrial DNA sequences. Mol. Phylogenet. Evol. 16, 308-315.

Bernstein, S. and Bernstein, R. (2002) Allometry of male genitalia in a species of soldier beetle: support for the one-size-fits-all hypothesis. Evolution 56, 1707-1710.

Blanckenhorn, W.U., Kraushaar, U. and Reim, C. (2003) Sexual selection on morphological and physiological traits and fluctuating asymmetry in the yellow dung fly. J. Evol. Biol. 16, 903-913.

Burkhardt, D., de la Motte, I. and Lunau, K. (1994) Signalling fitness: larger males sire more offspring. Studies of the stalkeyed fly Cyrtodiopsis whitei (Diopsidae: Diptera). J. Comp. Physiol. A 174, 61-64.

Danielsson, I. and Askenmo, C. (1999) Male genital traits and mating interval affect male fertilization success in the water strider Gerris lacustris. Behav. Ecol. Sociobiol. 46, 149-156.

Darwin, C. (1874) The Descent of Man and Selection in Relation to Sex; by Prometheus Books. Amherst, New York, reprinted in 1998.

Dixson, A.F. (1998) Primate Sexuality. Oxford University Press.

Eberhard, W.G. (1985) Sexual Selection and Animal Genitalia. Harvard University Press, Cambridge, MA, USA.

Eberhard, W.G. (1994) Evidence for widespread courtship during copulation in 131 species of insects and spiders, and implications for cryptic female choice. Evolution 48, 711-733.

Eberhard, W.G. (1996) Female Control: Sexual Selection by Cyptic Female Choice. Princeton University Press, Princeton.

Eberhard W.G., (1997) Sexual selection by cryptic female choice in insects and arachnids. In J.C. Choe and B.J. Crespi (eds) The Evolution of Mating Systems in Insects and Arachnids, Cambridge University Press, pp. 32-57.

Eberhard W.G., (1998) Female roles in sperm competition. In T.R. Birkhead and A.P. Møller (eds.) Sperm Competition and Sexual Selection, Academic Press, pp. 91-118.

Eberhard, W.G. (2001) Species-specific genitalic copulatory courtship in sepsis flies (Diptera, Sepsidae, Microsepsis). Evolution 55, 93-102.

Eberhard, W.G. (2002) The relationship between aggressive and sexual behavior and allometry in Palaeosepsis dentiformis flies (Diptera: Sepsidae). J. Kansas Entomol. Soc. 75, 317-332.

Eberhard, W.G., Huber, B.A. and Rodriguez, R.L. (1999) Dont forget the biology: a reply to Green. Evolution 53, 1624-1627.

Eberhard, W.G., Huber, B.A., Rodriguez, R.L., Briceño, R.D., Salas, I. and Rodriguez, V. (1998) One size fits all? Relationship between the size and degree of variation in genitalia and other body parts in twenty species of insects and spiders. Evolution 52, 415-431.

Fairbairn, D.J., Vermette, R., Kapoor, N.N., and Zahiri, N. (2003) Functional morphology of sexually selected genitalia in the water strider Aquarius remigis. Can. J. Zool. 81, 400-413.

Felsenstein, J. (1985) Phylogenies and the comparative method. Am. Nat. 125, 1-15.

Gage, M.J.G. (1994) Associations between body size, mating pattern, testis size and sperm lengths across butterflies. Proc. Roy. Soc. London B 258, 247-254. 
Gage, M.J.G. (1998) Influences of sex, size, and asymmetry on ejaculate expenditure in a moth. Behav. Ecol. 9, 592-597.

Gage, M.J.G. and Freckleton, R.P. (2003) Relative testis size and sperm morphometry across mammals: no evidence for an association between sperm competition and sperm length. Proc. Roy. Soc. London B 270, 625-632.

Gage, M.J.G., Stockley, P. and Parker, G.A. (1995) Effects of alternative male mating stratgies on characteristics of sperm production in the Atlantic salmon (Salmo salar): theoretical and empirical investigations. Philos. Trans. Roy. Soc. B 350, 391-399.

Grafen, A. (1987) Measuring sexual selection: why bother?. In J.W. Bradbury and M.B. Andersson (eds.) Sexual Selection: Testing the Alternatives, John Wiley and Sons, New York, pp. 221-233.

Green, A.J. (1992) Positive allometry is likely with mate choice, competitive display and other functions. Anim. Behav. 43, 170-172.

Green, A.J. (1999) Allometry of genitalia in insects and spiders: one size does not fit all. Evolution 53, $1621-1624$.

Gwynne, D.T. (1998) Genitally does it. Nature 393, 734-735.

Hackman, W. (1956) The Scathophagidae (Dipt.) of Eastern Fennoscandia. Fauna Fennica II, Tilgmann, Helsingforsiae 1-67.

Harcourt, A.H., Harvey, P.H., Larson, S.G. and Short, R.V. (1981) Testis weight, body weight and breeding system in primates. Nature 293, 55-57.

Hellriegel, B. and Blanckenhorn, W.U. (2002) Environmental influences on the gametic investment of yellow dung fly males. Evol. Ecol. 16, 505-522.

Hosken, D.J. (1997) Sperm competition in bats. Proc. Roy. Soc. London B 264, 385-392.

Hosken, D.J. (1998) Testes mass in megachiropteran bats varies in accordance with sperm competition theory. Behav. Ecol. Sociobiol. 44, 169-177.

Hosken, D.J., Meyer, E.P. and Ward, P.I. (1999) Internal female reproductive anatomy and genital interactions during copula in the yellow dung fly, Scathophaga stercoraria (Diptera: Scathophagidae). Can. J. Zool. 77, 1975-1983.

Hosken, D.J. and Stockley, P. (2004) Sexual selection and genital evolution. Trends Ecol. Evol. 19, $87-93$.

Hosken, D.J. and Ward, P.I. (2001) Experimental evidence for testis size evolution via sperm competition. Ecol. Lett. 4, 10-13.

House, C.M. and Simmons, L.W. (2003) Genital morphology and fertilization success in the dung beetle Onthophagus taurus: an example of sexually selected male genitalia. Proc. Roy. Soc. London B 27, 447-455.

Kelly, C.D., Godin, J.G.J. and Abdallah, G. (2000) Geographic variation in the male intromittent organ of the Trinidadian guppy (Poecilia reticulata). Can. J. Zool. 78, 1674-1680.

Kirkpatrick, M. and Ryan, M.J. (1991) The evolution of mating preference and the paradox of the lek. Nature 350, 33-38.

Knell, R.J., Pomfret, J.C. and Tomkins, J.L. (2004) The limits of elaboration: curved allometries reveal the constraints on mandible size in stage beetles. Proc. Roy. Soc. London B 271, 523-528.

Kraushaar, U. and Blanckenhorn, W.U. (2002) Population variation in sexual selection and its effects on size allometry in two dung fly species with contrasting sexual size dimorphism. Evolution 56, 307-321.

Kraushaar, U., Goudet, J. and Blanckenhorn, W.U. (2002) Geographical and altitudinal population genetic structure of two dung fly species with contrasting mobility and temperature preference. Heredity 89, 99-106.

Losos, J.B. (1999) Uncertainty in the reconstruction of ancestral character states and limitations on the use of phylogenetic comparative methods. Anim. Behav. 58, 1319-1324.

Lüpold, S., McElligott, A.G. and Hosken, D.J. (2004) Bat genitalia: allometry, variation and good genes. Biol. J. Linnean Soc. 83, 497-507.

Minder, A.M. (2002) Co-evolution of sperm, testis and female reproductive tract morphology in Scathophagidae. Diploma Thesis, University of Zürich.

Minder, A.M., Hosken, D.J. and Ward, P.I. (2005) Co-evolution of male and female reproductive characters across the Scathophagidae. J. Evol. Biol. 18, 60-69. 
Merz, B., Baechli, G., Haenni, J.-P. and Gonseth, Y. (1998) Fauna Helvetica Diptera-Checklist. 1st edn. Schweizerische Entomologische Gesellschaft, Neuchâtel, pp. 311-312.

Otronen, M. (1998) Male asymmetry and postcopulatory sexual selection in the fly, Dryomyza anilis. Behav. Ecol. Sociobiol. 42, 185-192.

Parker, G.A. (1970) Sperm competition and its evolutionary consequences in the insects. Biological Reviews 45, 525-567.

Parker, G.A., Ball, M.A., Stockley, P. and Gage, M.J.G. (1997) Sperm competition games: a prospective analysis of risk assessment. Proc. Roy. Soc. London B 264, 1793-1802.

Petrie, M. (1988) Intraspecific variation in structures that display competitive ability: large animals invest relatively more. Anim. Behav. 36, 1174-1179.

Petrie, M. (1992) Are all secondary sexual display structures positively allometric and, if so, why? Anim. Behav. 43, 173-175.

Pitnick, S. (1996) Investment in testes and the costs of making long sperm in Drosophila. Am. Nat. 148, $57-80$.

Pitnick, S., Miller, G.T., Reagan, J. and Holland, B. (2001) Evolutionary responses by males to experimental removal of sexual selection. Proc. Roy. Soc. London B 268, 1071-1080.

Pomiankowski, A. and Møller, A.P. (1995) A resolution to the lek paradox. Proc. Roy. Soc. London $B$ 260, 21-29.

Rodriguez, V., Windsor, D.M. and Eberhard, W.G. (2003) Tortoise beetle genitalia and demonstrations of sexually selected advantage for flagellum length in Chelymorpha alternans (Chrysomelidae, Cassidini, Stolaini). In P. Jolivet, J.A. Santiago-Blay and M. Schmitt (eds.) New Developments on the Biology of Chrysomelidae, SPB Academic Publishing, pp. 739-748.

Rowe, L. and Houle, D. (1996) The lek paradox and the capture of genetic variation by condition dependent traits. Proc. Roy. Soc. London B 263, 1415-1421.

Sack, P. (1937) 62a Cordyluridae. In Lindner (eds.) Die Fliegen der Palaearktischen Region7 E. Schweizerbart'sche Verlagsbuchhandlung, Stuttgart, pp. 1-103.

Schmitz, G., Reinhold, K. and Wagner, P. (2000) Allometric relationship between genital size and body size in two species of mordellid beetle (Coleoptera: Mordellidae). Ann. Entomol. Soc. Am. 93, 637-639.

Sigurjonsdottir, H. and Parker, G.A. (1980) Dung fly struggles: evidence for assessment strategy. Behav. Ecol. Sociobiol. 8, 219-230.

Simmons, L.W. and Tomkins, J.L. (1996) Sexual selection and the allometry of earwig forceps. Evol. Ecol. 10, 97-104.

Sokal, R.R. and Rohlf, F.J. (1981) Biometry. 3rd edn. W.H. Freeman, San Francisco.

Stockley, P. (2002) Sperm competition risk and male genital anatomy: comparative evidence for reduced duration of female sexual receptivity in primates with penile spines. Evol. Ecol. 16, 123-137.

Stockley, P., Gage, M.J.G., Parker, G.A. and Møller, A.P. (1997) Sperm competition in fishes: the evolution of relative testis size and ejaculate characteristics. Am. Nat. 149, 933-954.

Tatsuta, H., Mizota, K. and Akimoto, S.-I. (2001) Allometric patterns of head and genitalia in the stag beetle Lucanus maculifemoratus (Coleoptera: Lucanidae). Ann. Entomol. Soc. Am. 94, 462-466.

Tomkins, J.L. and Simmons, L.W. (2002) Measuring relative investment: a case study of testes investment in species with alternative mating tactics. Anim. Behav. 63, 1009-1016.

Uhl, G. and Volrath, F. (2000) Extreme body size variability in the golden silk spider (Nephila edulis) does not extend to the genitalia. J. Zool., London 251, 7-14.

Vockeroth, J.R. (1989) Scathophagidae. In J.F. McAlpine and D.M. Wood (eds.) Manual of Nearctic Diptera. 2nd edition Agriculture Canada, Research Branch, Ottawa, pp. 1085-1097.

Ward, P.I. and Simmons, L.W. (1991) Copula duration and testis size in the yellow dung fly, Scathophaga stercoraria (L.): the effects of diet, body size, and mating history. Behav. Ecol. Sociobiol. 29, 77-85.

Zaka-ur-Rab, M. (1979) Morphology of the male terminalia of Scathophaga stercoraria L. (Diptera: Scatophagidae). J. Entomol. Res. 3, 25-31.

Zar, J.H. (1999) Biostatistical Analysis. Prentice-Hall, NJ. 